\title{
The Effect of Stocking Density on The Growth and Survival Rate of Juvenile Seahorses (Hippocampus barbouri)
}

\author{
Muhammad Syukri', Nurhikma Ramadhana ${ }^{2}$ \\ \{muhammadsyukri@unsulbar.ac.id ${ }^{1}$, nurhikma@unsulbar.ac.id ${ }^{2}$ \} \\ ${ }^{1,2}$ Universitas Sulawesi Barat, Jl. Prof. Dr. H. Baharuddin Lopa, SH., Majene, West Sulawesi, \\ 91412, Indonesia.
}

\begin{abstract}
This study aims to find outthe effects of stocking density on the growth of length, weight and survival rate of juvenile seahorses (Hippocampus barbouri). The expected output of this study would be some informations for the development of hatcheries and numerous subsequent studies. This study uses 4 treatments with 3 repetitions so that there are 12 experimental unit. The results showed that the different stocking densities had no significant effect on the rate of growth in length and weight of juvenile seahorses (Hippocampus barbouri), whereas the different stocking densities had a significant effect on the survival rate of juvenile seahorses (Hippocampus barbouri), where the highest survival ratefor the preservation of juvenile seahorses was obtainedat the stocking density of 2 tails / liter.
\end{abstract}

Keywords: Stocking Density, Length, Weight, Survival Rate, Marine Culture,Sustainable Cultivation.

\section{Introduction}

Suggests that Indonesian waters are the richest in terms of the variety of marine ornamental fish compared to some other ornamental fish producer countries [1]. In Indonesia alone there are approximately 253 species of ornamental fish, one of which is the sea horse. Seahorses are unique and commercial because they have different morphologies with the other fish. The seahorses head resembles the shape of the horsehead and themale ones have an incubation pouch that is not found in the other types of fish. Another attraction is their upright body position while swimming as well as their ability to customize the color of the body with the environment, which is looked more attractive for the display in the aquariums. The seahorses can also beused asa raw materialfor traditional medicine and souvenir.

As a maritime country with two thirds of the territory is water, Indonesia has the potential of diverse ornamental fish, with 253 species of ornamental fish, making Indonesia the world's richest countries for ornamental fish producer compared to the other tropical countries. Seahorses (Hippocampus sp) is one of the fish species foundin Indonesia [2]. Seahorse is actually a type of ornamental fish with a quite high market value. In this case, they are offered in the domestic market as well as the foreign markets. Each year no less than 20 million head of dried Seahorses and hundreds of thousands of live seahorses captured and traded by approximately 40 countries, including Indonesia. Among the renowned Seahorse exporting countries in the world are China, Taiwan, Hong Kong, Thailand, Vietnam, India, Philippines and Indonesia [2]. Moreover, the marketing of seahorses are usually done in several ways. In 
this case, alive seahorse is used for ornamental fish, whereas the dried seahorse is marketed as a traditional medicine to cure paticular sexual problems, as well as souvenir [3].

However, this condition significantly intensifies the capture of the seahorses in the natureand thus, endangering their sustainability. One of the efforts to preserve the seahorse is by developing towards cultivation. One aspect of cultivation worth to know is the cultivation through a stocking density. In this case, the stocking density is concerned with the age and size of a species, which is a decisive factor in making an optimum production [4].

Stocking density requires the number of individuals being stocked in a particular container. [5] explainsthat the number of fish that are too dense will hinder growth, it is because the fish interferes with each other. Spreading the congested area will result in less movement and will indirectly affect the desire to eat fish.

[6] Says that one of the factors influencing the growth in length and weight are stocking density. High stocking density will lead to high mortality as well as well as the lower rate of growth and survival rate. [7] adds that with the increase in the larval stocking density, the pressure on the media environment becomes increasingly heavy because of the increased competition space, the need for food and the influence of metabolic waste from the larvae, which in turn lowers the survival rate of these live juveniles.

[1] Said that too many organisms in waters that are not balanced with the amount of food will lead to the competition for food. The success of getting food will determine the growth that ultimately affect the survival rate. [8] adds that the rivalry or competition in getting the food results in the stunted growth. Growth can be defined as the length or weight in a time [9]. It also said that growth would occur if there is an input of energy and protein from food. [10] Stated that growth occurs when the amount of food ingested exceeds the amount of food needed for body maintenance.

The preservation of the juvenile seahorses with regular feeding will give the best results on growth, especially in the areas exposed to direct sunlight, which will renders good results in growth and graduation of their life. The growth of the seahorses is affected by their behavior or eating habits. The active juvenile seahorses eat during the day and becomes less active at night. The juvenile seahorses that are too late to eat for 12 hours are unlikely to eatat all in the next night, and this might inhibit the growth and even cause the death [8].

[11] Says that the same growth can be achieved when the same foodare given, and weight and length of the fish at the beginning are also the same. Furthermore it is said that the growth influenced by several factors such as the conditions of life, temperature, quality and quantity of food provided and the concentration of oxygen.

Growth is a function of the internal factors and environmental factors. Environmental factors in question includedensity [5] and the availability of food [12]. The higher the stocking density the higher the competition for the space and food, so that growth characterized by the weight of individuals is getting lower when the stocking density is higher [4]. [13] says that the growth of the fish can be influenced by the environmental factors such as light intensity, temperature, dissolved oxygen, stocking density and the amount of food and the quality of food given. [11] explains that some factors in the body that influence growth include heredity, age, disease resistance and the ability to use food.

The survival rate reached by a population illustrates the result of interaction between environmental carrying capacity and the existing population response. The main factors that influence it, namely the density and the amount of food [14]. [15] Suggested that a minimum density of the food and the increasing density of the food do not cause significantly different results on the growth and survival rate. While the amount of food that is below the critical level will result in the slow growth and high death rates. 
The low survival rate of juvenile seahorses happens when the stocking density is inadequate or less than the amount of food, causing competition for food. Juvenile seahorses are weak and do not manage to get the food while the strong ones will continue to look for the food. [3] Said that the availability of food is one factor that determines the success during the preservation of juvenile seahorses. Type, quality, dose and the right frequency of feeding positively influence the survival rate of juveniles seahorses. Furthermore it is said that the initial feeding of copepods at a dose of 3-5 fish $/ \mathrm{ml}$ water gives good results on the growth of juvenile sea horse aged 1 to 2 days with a survival rate reaches $33-57 \%$.

[12] Suggested that the death during the preservation of seahorses usually occur during the early process until 30 days due to a failure in the process of osmoregulation and high temperature fluctuations. Previous research by Sudaryanto, obtaining a $30 \%$ survival rate at day 11-15 with initial density 1000-1500 tail/ton, and the survival rate of 23.3 to $38.5 \%$ were maintained for 30 days. [16] alsogot $38.4 \%$ survival ratefor several attempts of the juvenile seahorses preservation up to the age of 30 days with initial density 500-1500 tails / ton. Several other studies have also been conducted but yet to provide the maximum results, so it is necessary to do a further research on the maintenance of juvenile seahorses in a container controlled at different stocking density, which will support the development of hatchery up towards cultivation.

\section{Research Method}

The research was conducted at the Institute of Fisheries Budidadaya Brackish Water (BPBAP) Takalar from June till July 2016, Meppakalompo Rural District of South Galesong Takalar South Sulawesi Province.

In the early stage, the research was conducted by preparing containers and tools used in the study. For water treatment, this study used a cartridge filter and 1 micron filter bag. Each container was equipped with aeration and shelter/substrate where the juveniles wrapped his tail to.

Furthermore, the research container was prepared,; as many as 10 pieces of glass aquariumswith the size of $60 \times 80 \times 60 \mathrm{~cm} 3$ for the parent's adaptation. For maintenance and breeding, 12 units glass aquarium sized $50 \times 35 \times 34 \mathrm{~cm} 3$ were used. 12 units of small aquariums sized $20 \times 20 \times 20 \mathrm{~cm} 3$ were used for the juveniles preservation. Each container is equipped with a filter system, aeration and perch (shelter).

The parents of the sea horseswere obtained from Lantang Peo Island in Tanakeke Archipelagoof the catches of fishermen with the average length of the male parent and a female parent ranges from $12-13 \mathrm{~cm}$. The seahorses parents were firstly inserted into the container aquarium of $80 \times 60 \times 60 \mathrm{~cm} 3$ to be adapted for 1 week. Afterwards, they were put into the aquarium of $50 \times 35 \times 34 \mathrm{~cm} 3$ in the ratio of $1: 1$. Food given was jembret (Mesopodopsis $s p$ ) with the frequency of feeding 2 timesper dayby ad libitum.

The juvenile seahorses obtained from spawning were put into the research aquarium sized $20 \times 20 \times 20 \mathrm{~cm} 3$ with different stocking densities in accordance with the treatment. The average length of juveniles is $1,36 \mathrm{~cm}$ with the overall length ranges from 1,30 to $1,40 \mathrm{~cm}$, while the average weight of juveniles is 0,02 grams. Juvenile Seahorses were kept for 30 days. Food given in the form of Artemia salina with the density of 1 tail / $\mathrm{ml}$ and the frequency of feeding 3 times per day.

The experimental design used in the study is a completely randomized design (CRD) with 4 treatments and 3 repetitions as follows:

$>$ Treatment $\mathrm{A}=$ Density 2 tails $/$ liter 
$>$ Treatment $\mathrm{B}=$ Density 3 tails / liter

$>$ Treatment $\mathrm{C}=$ Density 4 tails $/$ liter

$>$ Treatment $\mathrm{D}=$ Density 5 tails / liter

There are 12 experimental units in overall and the containerswere placed randomly. The layout of the experimental units after the randomization can be seen in Figure 1.

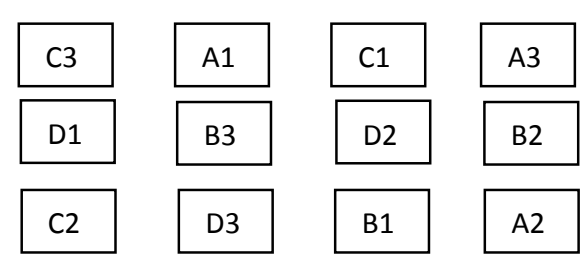

Figure 1. The layout of container research

Measurement of length and weight growth was done every 7 days by measuring the length of the body of juvenile seahorses using a ruler from the crown to tip of tail vertically and weighing the body of juvenile seahorses using electric scales with the accuracy of 0.1 gram.

To calculate the growth rate of the weight and individual lengths of juvenile seahorses, this study used the formula [17] :

1. Daily Growth Rate of Individual Juvenile Seahorse Weight

$$
\mathrm{Wt}=\mathrm{Wo}(1+0,01 \alpha)^{\mathrm{t}}
$$

Note: $\alpha=$ Percentage of daily growth (\%)

Wo $=$ Weight average timeto-o $(\mathrm{g})$

$\mathrm{Wt}=$ Weight average time to- $\mathrm{t}(\mathrm{g})$

$\mathrm{t}=$ time of observation (day)

2. Daily Growth Rate of Individual Juvenile Seahorse Length

$$
\mathrm{Lt}=\operatorname{Lo}(1+0,01 \alpha)^{\mathrm{t}}
$$

Note: $\alpha=$ Percentage of daily growth (\%)

Lo $=$ The average length of juveniles time to-o $(\mathrm{g})$

$\mathrm{Lt}=$ The average length of juveniles time to- $\mathrm{t}(\mathrm{g})$

$\mathrm{t}=$ time of observation (day)

3. Survival Rate

The observations of survival ratewas carried out at the end of the study by counting the number of juvenile seahorses alive.

$$
\mathrm{SR}=\frac{\mathrm{Nt}}{\mathrm{No}} \times 100 \%
$$

Note: $\mathrm{SR}=$ Survival rate $(\%)$

No $=$ Number of juveniles at the beginning of the experiment (tail)

$\mathrm{Nt}=$ Number of juveniles living at the end of the experiment (tail)

4. Water Quality

As the supporting data, this study involves the daily measurement of water quality with the parameters include: salinity, temperature, $\mathrm{pH}$ and dissolved oxygen. While the measurement of Ammonia $\left(\mathrm{NH}_{3}\right)$ was done every 7 days during the measurement of the growth of juvenile seahorses. In addition, the suction was done at the bottom of the container to clean up the waste and residue. 


\section{Statistical Analysis}

To determine the effect of stocking density on the growth and survival rateof juvenile seahorses, the analysis of variance is applied. If the treatment is proven to be significantly affecting the growth and the survival rate of seahorses, then it will be continued with the Least Significant Difference test to determine the best treatment [18].

\section{Results and Dicussion}

\section{a. Growth Length and Weight Rate}

The growth in length and weight of juvenile seahorses foreach treatment can be seen in Figures 3 and 4. Figure 3 shows that the long growth of juvenile seahorses are increasing with theincreasing time of the research. The average length was initally at $1.36 \mathrm{~cm}$ at, reaching an average length of $3.25 \mathrm{~cm}$ for the treatment $A, 3.21 \mathrm{~cm}$ for the treatment $\mathrm{B}, 3.08 \mathrm{~cm}$ for the treatment $\mathrm{C}$, and $3.06 \mathrm{~cm}$ for the treatment $\mathrm{D}$, even though the results of ANOVA showed that the growth of the length of the sea horses did not occur significantly among each treatment $(0.159$, means $\mathrm{P}>0.05)$. Figure 3 also shows that in treatment $\mathrm{A}$ with a stocking density of 2 tails/liter,the juvenile length grew better compared to the three other treatments, this is because the stocking density tends to result in smaller oxygen consumption so that the oxygen supply in the container higher. It can be seen in table 4 that the results of water quality measuremant is $5.74 \mathrm{mg} / 1$, where the dissolved oxygen content is higher when compared to the other three treatments. Besides, the lowest ammonia levels are found in treatment $\mathrm{A}$ with a solid stocking of 2 tails/liter with ammonia levels of 0.0030 . This is fairly low compared to ammonia levels in the other three treatments, as the higher ammonia levels can inhibit the growth rate of the organisms that are maintained in a cultivation container. More details can be seen in Figure 2 below.

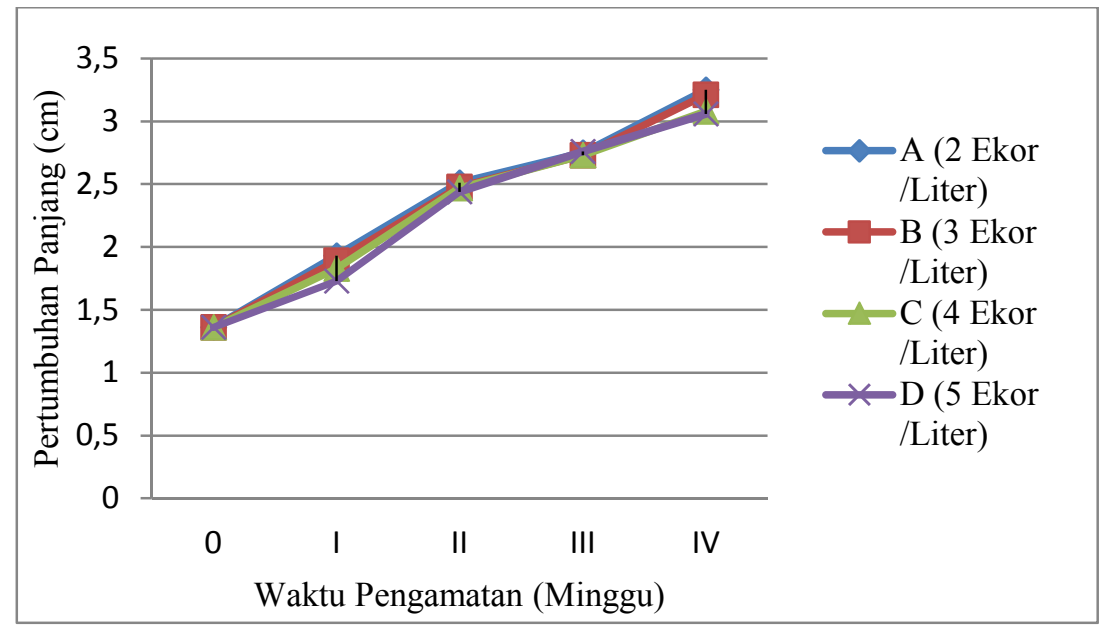

Figure 2. The Average Growth of juvenile Seahorses Length

Figure 3 shows that the initial weight of the seahorseswas at the average of 0.020 grams at the start of the study, and has reached up to the average weight of 0.138 gram for treatment $\mathrm{A}$, 0.132 gram for the treatment of $\mathrm{B}, 0.108$ gram for treatment $\mathrm{C}$, and 0.103 gram for the treatment $\mathrm{D}$ at the end of the research. Figure 4 also shows that the growth of sea horse 
juvenile weight is better in treatment A with a stocking density of 2 tails/liter when compared to the other three treatments, although the anova results indicate that there is no significant difference between the 4 treatments $(0.093$ means $\mathrm{P}>0,05)$. The treatment with the stocking density of 2 tails / liter shows a better weight growth since the small stocking density does not result in the competition forthe dissolved oxygenor food consumption, so that the growth can be better maximized compared to the three other treatments.

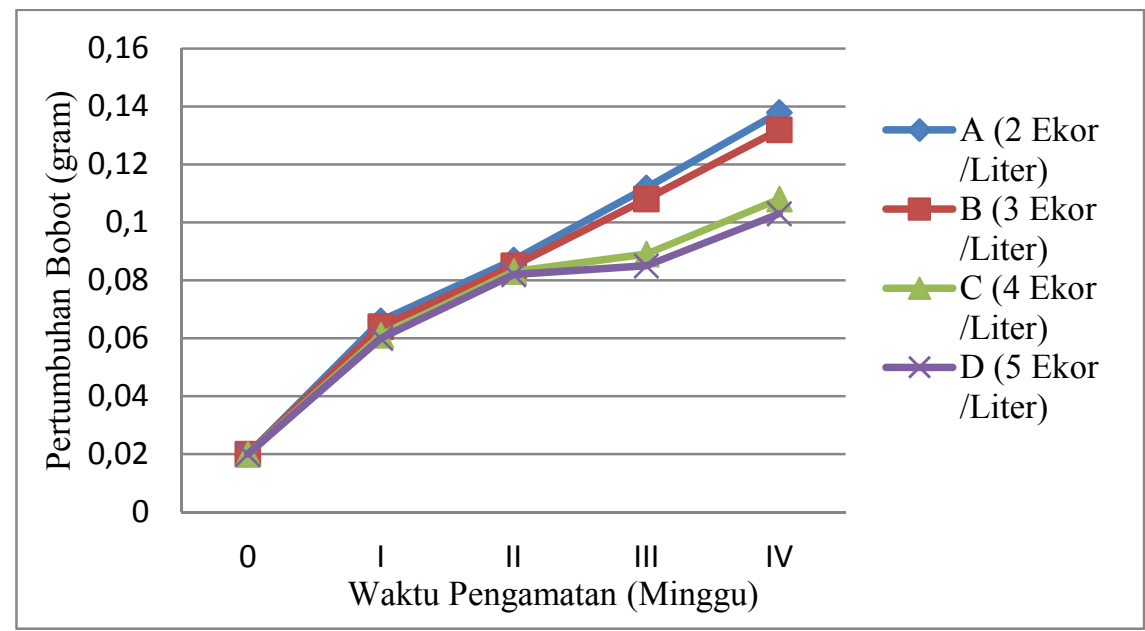

Figure 3. The Average Growth Weight of Juvenile Seahorses

The average growth rate in length and weight of juvenile seahorses can be seen in Table 1. It indicates that the stocking density did not significantly affect both the daily length growth, as well as the daily weight growth of juvenile seahorses. This is because in the treatment $C$ and $D$, the death of juvenile sea horsesoccurred for as much as $\pm 45 \%$, so that the density would be the same with the treatment A and B. So, with the same density, the amount of food given to each of the treatments is also the same and this causes no difference in the growth of length and weight of juvenile sea horse.

Table 1. The Average Growth of Weight and Length and Survival Rate of Juvenile Seahorses

\begin{tabular}{lcccc}
\hline \multirow{2}{*}{ Parameter } & \multicolumn{4}{c}{ Treatment } \\
\cline { 2 - 5 } & $\begin{array}{c}\text { A (2 tails } \\
\text { /liter) }\end{array}$ & $\begin{array}{c}\text { B (3 tails } \\
\text { /liter) }\end{array}$ & $\begin{array}{c}\text { C (4 tails } \\
\text { /liter) }\end{array}$ & $\begin{array}{c}\text { D (5 } \\
\text { tails } \\
\text { /liter) }\end{array}$ \\
\hline $\begin{array}{l}\text { Growth Rate of Juvenile Seahorses } \\
\text { Length (\%) }\end{array}$ & $\begin{array}{c}3.041 \pm \\
0.083^{\mathrm{a}}\end{array}$ & $\begin{array}{c}2.961 \pm \\
0.062^{\mathrm{a}}\end{array}$ & $\begin{array}{c}2.894 \pm \\
0.039^{\mathrm{a}}\end{array}$ & $\begin{array}{c}2.962 \pm \\
0.093^{\mathrm{a}}\end{array}$ \\
& & & & \\
Growth Rate of Juvenile Seahorses & $7.158 \pm$ & $6.236 \pm$ & $5.917 \pm$ & $5.978 \pm$ \\
Weight (\%) & $0.143^{\mathrm{a}}$ & $0.317^{\mathrm{a}}$ & $0.459^{\mathrm{a}}$ & $0.353^{\mathrm{a}}$ \\
$\begin{array}{l}\text { Survival Rate of Juvenile Seahorses } \\
\text { (\%) }\end{array}$ & $85.35 \pm$ & $83.23 \pm$ & $65.58 \pm$ & $63.12 \pm$ \\
\hline
\end{tabular}


Description : ${ }^{\text {a }}$ letter in the same line indicate the treatment had no significant effect $(\mathrm{P}>0.05)$

\section{b. Survival Rate}

The experiments obtained the survival rate of $85.35 \%$ for treatment A, $83.23 \%$ for treatment B, $65.58 \%$ for treatment $\mathrm{C}$, and $63.12 \%$ for treatment $\mathrm{D}$. Results of variance analysis (ANOVA) for the survival rate of sea horses shows that there was a significant difference between treatments A, B, C, and D with anova results in $0.017(\mathrm{P}<0.05)$ After continued with the Least Significant difference Test showed that treatment A and B were not significantly different, the treatment $\mathrm{A}$ and $\mathrm{C}$ were significantly different, the treatment $\mathrm{A}$ and $\mathrm{D}$ were significantly different, treatment B and C were significantly different, treatment B and D were significantlu different, while treatment $\mathrm{C}$ and $\mathrm{D}$ were not significantly different. Thus stocking 2 and 3 tails/liter gives the same effect on the survival rate.

Stocking density was not significantly different on the length and weight growth of juvenile seahorses, but significantly different to the survival rate of juvenile seahorses. This is because by feeding 2 tail $/ \mathrm{ml}$ for each treatment, the energy wasenough only to survive, but not to grow.

The survival rate in treatment $\mathrm{C}$ and Dwere lowsince amount of food was limited. Besides, the sea horse is actually apassivepredator that would just passively wait for the food to come near it and then attacked them with its long snout. This is considered to be one of the factors that lead to the low survival rate in treatment $\mathrm{C}$ and $\mathrm{D}$. This is because the chances of getting food in the treatment $\mathrm{C}$ and $\mathrm{D}$ were low when stocked in high densities. It can clearly be seen in Figure 4 below.

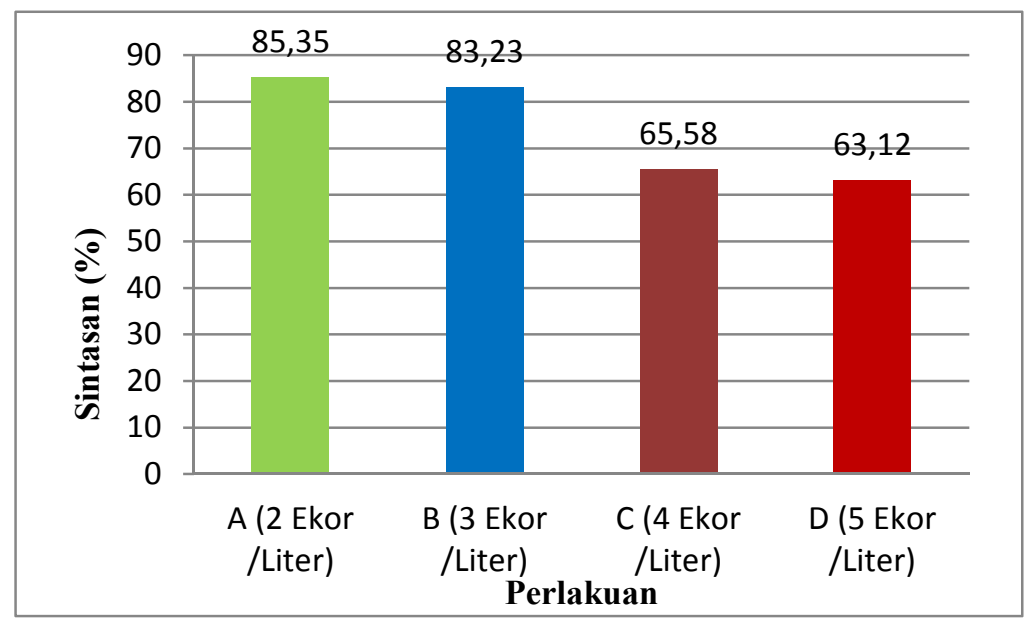

Figure 4. The Average Survival Rate of Juvenile Seahorse on each treatment 


\section{c. Water Quality}

Water quality is one important factor in the preservatiom of Seahorses. The results of the water quality measurement on the parameters such as average temperature, salinity, dissolved oxygen, $\mathrm{pH}$, and ammonia are in a reasonable range for the life of juvenile Seahorses as it clearly can be seen in Table 2 .

Table 2. The Average Results of Water Quality Measurements

\begin{tabular}{ccccccc}
\hline No & Treathment & $\begin{array}{c}\text { Temperature } \\
\left({ }^{\mathbf{0}} \mathbf{C}\right)\end{array}$ & $\begin{array}{c}\text { Salinity } \\
(\mathbf{p p t})\end{array}$ & $\mathbf{p H}$ & $\begin{array}{c}\text { DO } \\
(\mathbf{m g} / \mathbf{L})\end{array}$ & $\begin{array}{c}\text { Ammonia } \\
(\mathbf{p p m})\end{array}$ \\
\hline 1. & $\mathrm{~A}$ & 27 & 35 & 7.56 & 5.74 & 0.0030 \\
2. & $\mathrm{~B}$ & 27 & 35 & 7.54 & 5.72 & 0.0035 \\
3. & $\mathrm{C}$ & 27 & 35 & 7.52 & 5.68 & 0.0037 \\
4. & $\mathrm{D}$ & 27 & 35 & 7.51 & 5.65 & 0.0041 \\
\hline
\end{tabular}

The average water temperatureis $26^{\circ} \mathrm{C}$ during the preservation. The preservation of the seahorses at a temperature that exceeds the tolerance limit will cause a total mortality [19]. According to [3], a decent temperature range for the preservation of Seahorses is at $26^{\circ} \mathrm{C}$ $28^{\circ} \mathrm{C}$, and young sea horseshave a narrow temperature tolerance compared to the adult seahorses [19].

Salinity of water for preservation is $35 \mathrm{ppt}$, [4] reported that based the studies onseveral literatures, seahorses can live at a salinity of $15 \mathrm{ppt}$ to $35 \mathrm{ppt}$, but some seahorses are reared at a salinity of $30 \mathrm{ppt}-35 \mathrm{ppt}$, [20] adds that the salinity tolerance for young seahorses is narrower than the adult seahorses.

The average degree of acidity $(\mathrm{pH})$ during the preservation is 7.56 for treatment $\mathrm{A}, 7: 54$ for treatment $\mathrm{B}, 7: 52$ for treatment $\mathrm{C}$, and 7:51 for treatment $\mathrm{D}$. The broad $\mathrm{pH}$ fluctuations are very risky on the cultivation of Seahorses. The best $\mathrm{pH}$ level sare 7-8 [21].

The oxygen supply, using aeration during the preservation is able to support oxygen well. Dissolved oxygen during preservation was $5.74 \mathrm{mg} / \mathrm{L}$ for treatment $\mathrm{A}, 5.72 \mathrm{mg} / \mathrm{L}$ for the treatment of B, $5.68 \mathrm{mg} / \mathrm{L}$ for treatment $\mathrm{C}$, and $5.65 \mathrm{mg} / \mathrm{L}$ for treatment $\mathrm{D}$. This range is still quite decent for juvenile seahorses as expressed by [9], that the range of dissolved oxygen for the life of juvenile seahorses is $5-6 \mathrm{mg} / \mathrm{L}$. [16] adds that the male parent and is pregnant (incubate) and young seahorses during the growth requirea higher dissolved oxygen concentration.

The average level of ammonia during the preservation is $0.0030 \mathrm{ppm}$ for treatment $\mathrm{A}$, $0.0035 \mathrm{ppm}$ for treatment $\mathrm{B}, 0.0037 \mathrm{ppm}$ for treatment $\mathrm{C}$, and 0.0041 for treatment $\mathrm{D}$. Toprevent the increase in the level of ammonia then the purging is done on waste and feces of seahorses 2 times a day before feeding. Ammonia levels suitable for seahorse preservation are $<0.05 \mathrm{ppm}$ [9]. Mean while, according to [13], the safe range of ammonia for survival rate of seahorses is $0.01 \mathrm{ppm}$. This shows that in the preservation process, the ammonia level is still suitable for the survival rate of the seahorses.

\section{Conclusion}

Seahorses are a type of ornamental fish that is endangered and protected by the state due to the rampant exploitation activities. Hence, the rehabilitation and cultivation of the seahorses are necessaryto maintain their sustainability. 
The different stocking densitydoes not give a significant effect on the rate of growth in length and weight of juvenile seahorses (Hippocampus barbouri). However, the different density brings a significant effect on the survival rate of juvenile seahorses (Hippocampus barbouri). The highest survival rate for the preservation of juvenile seahorses obtained at the stocking density of 2 tails/liter.

Acknowledgments. The author would like to express a sincere appreciation to Mr. Dr. Ir. Akhsan Djalaluddin, MS asthe Rector of Universitas Sulawesi Barat, and also to Mr. Dr. Rahmat Hasanuddin as the Board of Trustees of Universitas Sulawesi Barat and also special thank to Prof. Datuk Dr. Khalil Shawkataly, F. I. M. M. M., and Muhammad Arsyad, Ph.D for the direction and guidance in writing the internationally reputed articles.

\section{References}

[1] Nontji, A.: Archipelago Sea. Publisher Djambatan. Jakarta, 2014.

[2] Foster and Vincent, A. C. J.: Life History and Ecology of Seahorses. Jurnal of Fish Biology, 2004.

[3] Al Qodri, A. H., Sudjiharno dan P. Hartono.: Sea Horse Growing Business Package (Hippocampus spp). Presented at the Meeting of Engineering Technology Dissemination Unit. DG Fisheries Cisarua, Bogor. 4 to 6 August, 2014.

[4] Mangampa, M., Burhanuddin dan H. S. Suwoyo.: Preliminary Study Pond Water Use as Sea Horse Media Maintenance Juwana (Hippocampus barbouri). Presented at the National Seminar Stimulating Agricultural Development through Optimization of Land Resources and Technology Application Specific Location. Coastal Fisheries Research Institute. Makassar, October 22 to 23, 2014.

[5] Hicking, C. F.: Fish Culture. Faber and Faber. London. 317 pp, 2012.

[6] Sudaryanto.: Copepods as Sea Horse Feed Earlier Juwana (Hippocampus spp). Agriculture department. Director General of Fisheries. Marine Aquaculture Centres Lampung. Raising sea Bulletin No. 9: 40-46, 2013.

[7] Yunus., I. Rusdi., K. Mahasetiawati dan T. Ahmad.: Mangrove Crab Larvae Maintenance Experiment Scylla serrata on Various Solid Spreading. Journal of Coastal Aquaculture Spreading Vol 10 (1): 19-26, 2014.

[8] Sudaryanto, \& A. H. Al Qodri.: Maintenance Juwana Seahorse (Hippocampus spp) in Controlled Tub. Agriculture department. Director General of Fisheries. Marine Aquaculture Centres Lampung. Bulletin of Marine Aquaculture No. 7: 10-16, 2013.

[9] Al Qodri, A. H.: Breeding Standart of Seahorse in Indonesia Presented to International Workshop on The Management and Culture of Marine Species Used in Traditional Medicine - Cebu. Philippines, 2013.

[10] Steffens, W.: Principles of Fish Nutrition. Ellish Horwood Ltd. John Wiley and Sns. New York , 2012.

[11] Huet, M.: Text Book Of Fish Culture: Breeding and Cultivation of Fish. Phoenix Press Inc. Queson City. Philipphines. 436 p, 2012.

[12] Cowey, E. M. and J. R. Sargent.: Fish Nutrition. P 383-492. in Russel, F.S and Yonge (eds). Advances in Marine Biology. Academic Press. London, 2012.

[13] Boyd, C. F.: Water Quality in Warm Water Fish Pond. Auburn University. Alabama, 2012.

[14] Krebs. C. J.: Ecology. The Experimental of Analysis of Distribution and Abudance. London. 894p, 2013.

[15] Lockyear, J.: Spawning Preliminary Study on Controlled Bak and Enlargement Seahorse 
KNYSNA (Hippocampus capensis). Departement of Icthyology and Fisheries Science Rhodes University. Graham Stown. South Africa, 2012.

[16] Al Qodri, A. H., Sudjiharno dan P. Hartono.: Sea Horse Breeding Engineering Technology (Hippocampus spp)". Directorate General of Marine Aquaculture Center. Lampung, 2013.

[17] Huisman, E. A.: Food Conversion Efficiences at Maintenance and Production Level for Carp (Cyprinus carpio Linn.) and Rainbow Trout (Salmo gaidner Ric.). Aquaculture 9 (2): 259-273., 2012.

[18] Hanafiah, K. A., MS.: Rancangan Design of Experiments: Theory and Applications. Manajement of PT King of Grafindo Persada. Jakarta, 2013.

[19] Zhang, B.: Seahorse (Hippocampus) Culture in China In Aquaculture Technology of Marine Valuable Animals. Translated by Peter Chen. Southern Central China Industry University, pp 162 - 174, 2013.

[20] Syukri Muhammad.: Kajian pemijahan berulang terhadap kualitas telur Kuda laut (Hippocampus barbouri) dalam wadah Terkontrol. Jurnal Galung Tropika. Universitas Muhammadiyah Pare-pare, 2016.

[21] Vincent, A. C. J.: Home Range Behaviour of The Monogomous Australian Seahorse. Jurnal of Project Seahorse, 2005. 